\title{
The problem of personal identity of man in the social and cultural world
}

\author{
Tatyana Torubarova ${ }^{1, *}$, Olga Dyachenko $^{1}$ \\ ${ }^{1}$ Kursk State University, 29, Radishcheva St., 305000, Kursk Russia
}

\begin{abstract}
The article is devoted to understanding the problem of human self-determination in the modern social and cultural space, in which the question of personal identity becomes a search for one's own individualization, a question of survival and preservation of man as such. The relevance of the study is determined by the process of dehumanization of modern society, a crisis of spirituality leading to the prevalence of destructive origins, to depersonalization and the destruction of the individual personal dimension of human existence. The leading approach to the study of this problem is the method of the ascent from the abstract to the concrete, which makes it possible to comprehend the being of man and the phenomena of his existence associated with it. In this study, we used the dialectical method and the hermeneutical analysis of texts by modern scholars who consider the problems of the philosophical foundations of personal identity in the modern social and cultural world. The connection between the constitution of the essential definitiveness of the human personality and the existential source of the human origin itself is shown. The influence of the social transformation processes on the methods and possibilities of self-identification of man, on his self-identity is revealed. The conducted analysis shows that the key problem of modern society is man himself as a subject of a technotronic-oriented civilization, in which his personal identity is not only a key factor in his existence, but also a fundamental link in the reconstruction of the wholeness of being.
\end{abstract}

\section{Introduction}

Understanding the current social and cultural situation is impossible without understanding our true "I", that acting and actual person, in which our true identity is embodied. The meaning of man, of his presence in the world increasingly draws us to the comprehension of our own individual fate, of the tragedy of man in the modern world. Man with his own destiny has not only become problematic for himself, but the problem of identity becomes a matter of human survival as such. Nowadays, issues of selfdetermination, freedom and responsibility of a personality are increasingly associated with anxiety for a lost world, with a search for a world in which commensurability, the restoration of the wholeness of being, which gives meaning to human existence, are possible.

\footnotetext{
* Corresponding author: ttorubarova@rambler.ru
} 
That is why turning to the problem of personal identity is today the focus of attention of researchers in various fields of scientific knowledge. Many authors note the influence of external factors on this process. For example, Maxwell McCombs, Donald L. Shaw, David H. Weaver point to changes in the social and political community of citizens [1], and Mark Freestone describes the problem of the risk of radicalization of society and increasing personality disorders [2]. The scientist M. Stanford highlights the positive features of cultural evolution in recent years and the possibility of "including man in a wider evolutionary synthesis" [3].

Many researchers from different countries today speak of the emergence of a new image of man, which is associated with the promotion of transhumanism ideas. Therefore, scientists today are concerned about this invasion into the biological foundations of human nature and are trying to predict the consequences of such interventions. This is discussed in the work of Elena Postigo Solana [4], Tom Koch [5], Riccardo Campa [6], Merlo Joshua [7].

Thus, at the beginning of the XXI century, in the social and cultural world new problems have arisen that have an undeniable impact on the formation of personal identity and psychological ties between people. The article by A. Sauchelli [8] is devoted to the study of this issue. The above mentioned circumstances, of course, require consideration of various contexts of identity itself in order to use mixed methods of personality research, as D. Karaś writes in his work [9].

The issues of personal identity, clarification of the essence of this concept, of its meanings are studied the works of Russian authors, such as E.S. Maslova, I.V. Lysak, D.S.Galchuk [10,11,12], and D.I. Rumbina [13] analyzes the particularities of the cultural development of personality in classical and non-classical philosophy.

\section{Relevance}

However, the topic of man's personal identity in the social and cultural world, which is characterized by ever-growing contradictions and new threats to the spiritual nature of man, has not been the subject of a special study.

History is characterized by an uncontrollably continuing obscuration of the world, the essential episodes of which are: the disappearance of the gods and the abandonment of man into world loneliness, God abandoned man and the world and the destruction of Heaven and Earth began. Finally, the universal standardization of man in his instrumental attitude to all things in existence and the predominance of mediocrity and banality as a result of this.

What we mean today by the world when we talk about the obscuration of the world. The world always exists, first of all, the world of spirituality. The animal has no world, because it is fitted into the natural environment purely organically. The obscuration of the world means the loosening up and devastation of the human spirit, the dispersal of human existence, the suppression of spirituality and its false interpretation. The loosening up and devastation of spirituality makes the current situation increasingly catastrophic. The spread of despiritualization means the depletion of spiritual energy. The life of people in an obscured world is getting devoid of meaning, because the world itself is deprived of its spiritual depth, from which the essential and the life-defining are always traced back to man, constantly return to him, prompting him to rise above all selfishness in order to remain in intense greatness. Everything that exists is relegated in its essential ranks and qualities, therefore, the inexhaustible diversity of things goes down to the same level in which the dimension of extent and quantity becomes dominant. In the present time, "We are entering a society of opportunities in which man is dragged into the orbit of the "industry of opportunities", the production of which depends on the smooth functioning of the social system" [14]. In the uncontrollable pursuit of infinity, the near and the distant, the heavenly 
and the worldly have disappeared, because the quantitative in itself has acquired its own and self-sufficient quality. The individual personal origin of human existence is eliminated by the predominance of an indifferent mass, which is not just a gloomy accident, but a special kind of destructive activity that destroys all essential ranks and dignities that have a world-creating and world-preserving character, that is, a spiritual impulse necessary for creating the world. The fury of a mass person, devoid of historical roots and foundations holding together the social fabric of life, has a demonic character. Demonism is a destructive evil that eliminates the very possibility of existential historical thinking, for thinking itself is nourished by envy and revenge.

The aim of our study is the analysis of the essential foundations of man in the modern social and cultural world, testifying to his personal identity.

\section{Materials and methods}

The methodological basis of this study is the method of the ascent from the abstract to the concrete, which allows to reveal insights into the problem of personal identity through the explication of the modes of human existence. Methods of structural and functional analysis were used to reveal the modes of self-determination of man in the modern social and cultural world. In the study of the philosophical foundations of personal identity, the principles of the systemic approach were used. Based on the dialectical method, the problem of value orientations as one of the properties of human identity and selfidentification in the modern social and cultural world was thought over.

\section{Discussion}

According to O.B. Bokareva, in the work dedicated to M. Foucault, "The mode of being established in modern thinking allows it to have two roles: to justify all positivities and to be present in the ordinary rank in the element of empirical things" $[15, \mathrm{p} .8]$. But what is the current prevailing way of thinking, which represents all things in existence in such a way as to constantly pursue all things in existence in its totality and affirm itself in this pursuit? What is the spirit of this way of representing all things in existence? What is the type of thinking that in its ideas and projects pursues everything in the pursuit of power and submission?

According to M. Heidegger, it is F. Nietzsche who gives the answer to the question of what the way of forming ideas with the help of "winking" thinking is. If man prevails in the world as an animal rationale, then this type of nature of human existence is expressed primarily in that way of comprehending all things existent, by which all that exists is established in the status of its objects and subjective states; this type of nature counterposes all things existent as objects and is consistent with these objects as with surrounding circumstances. What is the way of forming ideas regarding all things existent as objects? Through squinting. In medieval English, blenchen means "squint", "wink", "flicker." Squinting and winking is always to be tricky and playing along, that is, coordinating what is needed by mutual mental understanding, rather than figuring out the initial depth of truth. "Winking" thinking is flirting with the essential and the life-defining, playing through bluff to lower all spiritual. We all know the traditional image of Lenin with a sly squint and, as if constantly winking. Winking refers to such a representation and formation of ideas, which is devoid of any aspiration to comprehend the essential source of its own ideas, that is, the existential historical source of this kind of ideation. Through winking, we signal each other about special cases, we are, as it were, in the sphere and relationship of the conspirators. Any formation of ideas in itself turns out to be winking. A winking thought, forming ideas 
as if in a conspiracy and in a thieves' way, is determined by the spirit of revenge and a fierce attack. In this sense, Nietzsche spoke of the spirit of revenge.Vengeful envious thinking leads to the hollowing out of the language. The now widespread hollowing out of the language not only undermines the moral and aesthetic responsibility in using the language, but also poses a threat to the very essence of humanity. After all, verbally expressing a thought means saying being itself. But the hollowing out of the language means its falling out of its own element. And then language in the service of our will becomes an instrument of submission and domination over things; that is, it itself falls under the dominance of the metaphysics of subjectivity. And in themselves, all things in existence are perceived as the interconnection of cause and action, which we can efficiently and scientifically calculate and explain in the same scientific and philosophical way. We reason as if we had long and finally established what constitutes the truth of being. But before reasoning, man must first regain being in demand by being. Only then does a genuine restoration of the essence of man occur in himself and in his word. Doesn't this mean that man must comply with this existential requirement if he seeks to return to his own essence, that is, to become human? Thinking about what the essence of humanity is is called humanistic. The humanity of man lies in his essence, on the contrary, inhuman means outside his essence. But where from and how then is the essence of man defined? M. Heidegger believes: "it is still hidden from Nietzsche, as well as from the whole of preNietzsche metaphysics, to what extent the essence of man is defined from within the essence of being." But mentioning this thought of M. Heidegger, a researcher E.A. Rakhmanovskaya writes: "But from a retrospective, generalizing point of view, we cannot unconditionally accept Heidegger's conclusion" [16, p.128].

In the "Economic and Philosophical Manuscripts of 1844" K. Marx spoke of the need to recognize and reveal the humanity of man, and he found this essence of man in society, in its structure of social and economic relations, which determine the mode of production and reproduction, first of all, of human life. Rousseau spoke of a "natural" man, but for Marx this is a social man. That is, only in society the totality of all human needs is fulfilled, in other words, only in society the fulfillment of human nature is guaranteed. In contrast to Deitas Christianity saw humanitas homo. During the Renaissance, homo humanus was opposed to medieval homo barbarus, therefore stadium humanitas was opposed to Gothic scholasticism. And if humanism is understood as the aspiration of man to be free for the sake of his own humanity and this shows his main value, then the specificity of all humanism is defined by the way nature and human freedom are understood. Therefore, various ways are found to implement such concepts. Humanitas of every homo humanus is defined by the already established interpretations of nature and history, the world and the foundation of the world, that is, being as a whole. Special for all humanism is the way in which the essence of man is defined, that is, that which turns out to be the humanistic essence of man. It is argued that man truly dwells only in his essence, and from the requirement of this essence he has his own foundation. It was said that the predestination of man is to comprehend the essence of his being, and not just to explain the nature and history of his activity. It is clear that the human body is something essentially different from a living organism. Biologism is not overcome if we ascribe the soul to the human body, ascribe reason to the soul, in order to then sing praise to reason. Science studies man as an organism, but this does not mean that the essence of man lies in a scientifically explained body seen as an "organic" thing. Such an understanding has the same low degree of justification as the fact that the essence of nature was discovered in atomic energy. It is precisely due to the technical dominance of man that nature reveals itself to him with its atomic face, thereby hiding its fundamental essence. We cannot reduce the essence of man to the being of a living organism, just as defining the essence of man by appealing to his immortal soul, or the power of reason, or personality traits is also not enough. 
Of all that exists, it is most difficult for us to comprehend the essence of the phenomenon of life, due to the fact that the current social and cultural situation is characterized by "the disintegration of the value and semantic space of social norms, patterns of behavior and activity" [17]. On the one hand, living creatures are most closely connected with us; on the other hand, they are separate from our existential essence. It seems to the religious believing consciousness that the essence of the divine is closest to man, while much is alien to us in animals. We are more familiar with the essential distance that separates us from the divine than with our hardly comprehensible bodily congeniality with animals. Such thoughts cast a strange light on the predestination of man as animal rationale. Plants and animals reside in their respective environments, and they are never placed freely in relation to their being. We cannot say that they have their own world, because their environment does not need a meaningful language. After all, language in its essence is not an expression of the needs of living organisms. It is unlikely that the essence of language is comprehensible in terms of its symbolic nature or even in terms of the function of meaning.

Human existence turns out to be the definition of what man is in his life-defining essence. Speaking of human being, we answer the question about the "essence" of man, and not the question of whether there really is man among us or whether there is not one already among us. We are used to asking with constant inappropriateness about what man is or who he is. We are talking about the personal comprehension of man or the cognition of his objective essence, but both personal and objective either miss or falsely interpret the essential development of human existence in its history. An essential experience happens with us when it engenders within us that in which the existence of man himself happens, in which he is what he is. In the language of traditional philosophy, it sounds like this: the substance of man is his existence. But the term substantia is a translation of the Greek ov́бí $\alpha$, meaning the presence of what is real in the sense of operability, or else what is present in itself. Then the expression "the substance of man is his existence" means the way in which man in his own essence becomes present in terms of being. With such a definition of the essence of man, the humanistic interpretation of man as animal rationale or as personality, or as a spiritual-endowed-with-the-soul-social-bodily being is not discarded or claimed false. Rather, it reveals the fact that the higher determinations of man's essence in humanism still do not fulfill man's own dignity. In the current forms of humanism, humanitas of man is still not placed high enough. For it is clear that the intrinsic value of man does not lie in his being as a substance of all things in existence, as a "subject" among them, such a subject that he, as the ruler and administrator of the being of all things in existence, is able to and can afford, so to speak, the task of full fulfillment of the being of all things existent in one or another loudly proclaimed "objectivity". In social life, both the personal experience of individuation and self-determination, which goes back to the uniquely unrepeatable awareness of belonging to the whole, and the social guarantees of a harmonious reception of the fullness of such a variety of meanings are equally important.

Being fulfilled in our time, man's humanitas deprives him of any essence, and he turns out to be out of his own place in the Universe, that is, as if suspended in the universal vacuum. The ontology that modern science offers us, say, astrophysics and microphysics, with an ever-increasing degree of inertia, quickly moves away from the earth, looking for the origin of life in the super-telescopic source of galaxies, and the sources of nature in subatomic particles, while the earth itself is being deeper and deeper immersed in the element of the irrational. Physical cognition reveals its boundary in the principle of uncertainty. Axiology is increasingly slipping into the subjectivity of moral and aesthetic norms and values. Finally, literally understood sociality is easily intertwined with the antisocial aspirations of man, and globalist political thinking turns out to be the most dogmatic in its messianic claims. Since man in his ecstatic essence turns out to be 
constantly outside the current spatial and temporal environment, so far everywhere he meets only himself. In his modern essence, man sees the whole world as his own, even if he does not like this world in any way. In this kind of problematic horizon, caused by man's own essence, the unity of man with the being of the naturally existing is rejected. One mutually supports the other. The unity of the human essence with the being of all things existent is rejected on the grounds that this essence asserts man in the status of a substantial subject, therefore the whole environment, including the social context, is considered as internally devoid of its own meaning. The alliance of nature of all things existent splits into the opposite, expressed in the language of traditional metaphysics, of two attributes of being: the being of the essence of man, endowed with the activity of meaning attribution, and the dimension of all things in existence devoid of their own meanings. Therefore, the existence of all things existent is understood as Nothing (Hegel), which man must fill with his own meanings. Is this state of things not a manifestation of the human essence itself, and if so, what is this dominant essence?

Who are we, what made us what we are now and how - these and similar questions we meet in modern philosophical thought, in the works of E. Husserl and M. Heidegger, M. Weber and K. Jaspers, M. Foucault and other authors. Why, after the Renaissance, did Western European culture become a culture of rational forms of domination, usefulness and calculation, a culture full of rebellion and obedience, the predominance of social magic and massive control over individuation processes? Indeed, in the processes of individuation, the main mystery of sociality remains unsolved.

Through the Renaissance idea of humanitas the human personality began to recognize itself as legal, moral, political, etc. subject. Classical rationalism was widespread in the context of formation of legal law-governed self-identity. What was striking was not so much the monstrous cruelty of the executions as the political arbitrary actions of the monarchist power, which did not have legally justified and fixed judicial punishment procedures. Legal consciousness always appeals to the ideal norm, but it fulfills itself in the social phenomenon of a specific punitive system. The functioning legal order is determined by subordination modus operandi and represents a power relationship. The existing technique of punishment usually depends not so much on the nature of the crimes committed as on the need to install a certain regime of power relations. The nature of power and relations regarding power and submission in each historical era enshroud in themselves the deep structures of the political body of the individual. The body of a slave and the body of austerity, the producing body and the erotic body are the "body" of the functioning of the mechanism for maintaining certain dominion relations under certain conditions of sociality. Power organizes the "body" necessary for itself on the basis of unlawful relations, for right arises from the unright. Power has always sought not so much to learn as to "track down" the hidden depths of the social body in order to more effectively influence it. F. Nietzsche said that the past reproduces a special social memory through the "bloody mnemonics of punishment." It never goes away without blood, suffering, sacrifices, when man is forced to make himself a memory: a terrible sacrifice and hostage (which includes the primary sacrifice), amazing perversions (e.g. castration), angry ritual forms of all religious cults (and at the initial stages, all religions are systems of cruelty) - all this has its origin in every instinct that can be guessed in pain by powerful auxiliary means of mnemonics.

The archaic permeates the social and cultural foundations of modern man. In archaic societies, "sociality" is directly recorded on the human body: initiation rituals are inseparable from the rite of tattooing. The law of the archaic community is recorded on the body of an individual in the rite of initiation, that is, a tattoo transfers him from a "stupid" individual into a social one. Only painting makes the face and body socially significant. Thanks to various kinds of tattoos, only through this means, a face gains its social dignity and exists as such. In the tattoo, the individuality of the face is destroyed, but then it takes 
on a social appearance. Magical mutilations, scars and tattoos are designed to reinforce those mnemonic meanings with which the individual clearly reproduces on himself his inherent sociality. Those who have signs on their faces and bodies perceive each other as a clear demonstration of the laws of their "kind and tribe", as a collective soul in its bodily image. Imprinted bodily signs express the social, which is opposed to the biological. The social as if violently suppresses the biological, anchoring bodily the memory of archaic collectivity, which cannot be overcome even by cruel torture and under the fear of death. But there is an active power of forgetting, which grows as far as weakens the archaic sociality, which turns the body and face of everyone into a visual means of social or political memory. When the human body ceases to be the only surface for recording sociality covering a certain range of things and events, when an "ascending" line of individuation appears, then sociality ceases to act in an exhaustive and total way on the body, so the body may not only spontaneously rebuild and hide itself, but also transgress the prevailing form of sociality.

Social formlessness was opposed by the divine order of nature, the "speculative spiritual order." The idea of order was felt especially intensely, since order was not a given, but a task requiring urgent implementation. The nature of power is predetermined by a society devoid of the necessary structural articulation. A socially formless world is not a world in the literal sense of the word. Some means are required to make the environment of man a world inhabitable for him. The world of human life is always complex, but the complexity of the world must be somehow consistent with man's ability to recognize this complexity and fit it into that way of life that allows him to think and act. The very complexity of the world must correspond to that which man could personally understand, in which he could orient himself with his own means, and which would combine organically with his needs, abilities and knowledge. After all, "everything that exists and what is given to us has neither the necessity nor the fullness of existence, because all that we are dealing with is, in essence, only pieces, shatters, fragments, stumps. Even people, we ourselves, are just a "precious sketch", a fragment, a draft. It is impossible not to notice, not to feel its flaw. In any thing we find that this is only a part, we find a deep trace of a fracture, we see "the scar of its ontological mutilation" (J. Ortega y Gasset). Even if we take not an object but matter, which, it seems, serves as the basis of everything, then there also arises a suspicion that it is not self-sufficient, that it cannot itself inchoate its existence. It owes this to some other force. The same thing happens with the reality within us: at every moment we feel only an infinitesimal part of our inner being, and not our full real "I", which is hidden from us. Even the world as a whole, the totality of what is given to us, is only a colossal fragment. The world proclaims its nonexistence, shouts about what it lacks, and forces us to philosophize.

\section{Results}

Summarizing what has been said, we note that man as a subject of the modern social and cultural world requires an awareness of the tragedy of his individually personal presence in the world, lamenting about meaninglessness, imposture and deep depersonalization. The desperate search for self-determination turns into the loss of the human origin, the destruction of the foundations of human existence. That is why the problem of personal identity becomes not only a life-determining, but also a life-affirming task. Man's understanding of his borders and capabilities, his awareness of his responsibility, of his own self-worth as a meaning-forming factor of being that has no alibi, makes him a sane subject of his actions. Personal experience, felt as an experience of belonging to the whole, is a guarantee of harmonious fullness of meaning formations and a guarantee of the implementation of these meanings in the social and cultural world. 
Man is doomed to the eternal search for himself, for his inner integrity and unity, for that being that does not exist in the empirical world and which appeals to us and opens up in our presence as existential historical meaning that allows us to overcome our own homelessness and lack of shelter, to find that very identity, thanks to which man can recognize himself as such and be such.

\section{References}

1. M. Mccombs, D.L. Shaw, D.H. Weaver, Mass Communication and Society, 781-802 (2014) DOI: 10.1080 / 15205436.2014.964871

2. M. Freestone, International Review of Psychiatry 29(4), 310-312 (2017) DOI: 10.1080/09540261.2017.1344395

3. M. Stanford, Acta Biotheoretica 68(19) (2019) DOI: 10.1007 / s10441-019-09367-7

4. E. Postigo Solana, ARBOR 195(792), 1-10 (2019) DOI: 10.3989/arbor.2019.792n2008

5. T. Koch, Journal of Medicine and Philosophy 45, 179-192 (2020) DOI: 10.1093/jmp/jhz040

6. R. Campa, Studia Humana 8(4), 10-26 (2019) DOI: 10.2478/sh-2019-0027

7. J. Merlo, Scientia et Fides 7(2), 41-61 (2019) DOI: 10.12775 / SetF.2019.015

8. A. Sauchelli, Theoria, 1-10 (2019) DOI: 10.1111/theo.12205

9. D. Karaś, E. Topolewska-Siedzik, O. Negru-Subtirica, Studia Psychologica: Teoria et Praxis 1(18), 5-25 (2018) DOI: 10.21697 / sp.2018.18.1.01

10. E.S. Maslova, Humanitarian of the South of Russia 1(8), 87-94 (2019) DOI 10.23683 / 2227-8656.2019.1.6

11. I.V. Lysak, Bulletin of Tomsk State University. Philosophy. Sociology. Political Science 38, 130-138 (2017) DOI: 10.17223 / 1998863X / 38/13

12. D.S. Galchuk, Bulletin of the Buryat State University. Philosophy 7, 44-51 (2017) DOI: 10.18101 / 1994-0866-2017-5-44-51

13. D.I. Rumbina, Society: Philosophy, History, Culture 7(63), 92-97 (2019) https://doi.org/10.24158/fik.2019.7.17

14. A.S. Alekhnovich, Horizons of Humanitarian Knowledge 2, 17-28 (2017) DOI: 10.17805 / ggz.2017.2.2

15. O.B. Bokareva, International Journal of Humanities and Natural Sciences 2(2), 6-10 (2019) DOI: 10.24411 / 2500-1000-2019-10561

16. E.A. Rakhmanovskaya, F. Nietzsche, Philosophical School 3, 121-129 (2018) DOI: 10.24411 / 2541-7673-2018-00006

17. E.Yu. Pochtareva, Bulletin of Perm State University. Philosophy. Psychology. Sociology 4, 563-575 (2017) DOI: 10.17072 / 2078-7898 / 2017-4-563-575 